\title{
Fertilizantes e espaçamento entre plantas na produtividade da couve-da- Malásia
}

\author{
Wanessa Resende Ferreira ${ }^{1}$; Marli A. Ranal ${ }^{2}$; Fernando Antônio Reis Filgueira ${ }^{3}$ \\ ${ }^{1}$ Rua Santos Dumont 935, 38.400-026 Uberlândia-MG; ${ }^{2}$ UFU, Instituto de Biologia, C. Postal 593, 38.400-902 Uberlândia-MG; \\ ${ }^{3}$ Unidade Universitária de Ciências Agrárias de Ipameri, Rodovia GO-330, Anel Viário s/n, 75.780-000 Ipameri-GO; E-mail: \\ ranal@ufu.br.
}

\begin{abstract}
RESUMO
As brássicas têm sido objeto constante de pesquisa devido à sua importância na alimentação humana, seja pela quantidade consumida, pelo alto valor nutricional ou por sua elevada produtividade. Brassica chinensis var. parachinensis foi introduzida no Brasil, Uberlândia, em 1992, destacando-se em relação a outras brássicas por seu alto teor de vitaminas A e C, cálcio e ferro, estando pronta para consumo em aproximadamente 30 dias. A produtividade biológica e agronômica dessa variedade foi analisada utilizando-se três tipos de fertilizantes e três espaçamentos entre plantas, visando subsidiar sua produção em escala comercial. A área foliar, massa da matéria seca e taxa de crescimento absoluto foram significativamente maiores com adubação mineral em relação à adubação orgânica. Os maiores valores referentes à taxa de crescimento relativo e taxa assimilatória líquida foram registrados em plantas mantidas nos maiores espaçamentos $(30 \times 20$ e $30 \times 30 \mathrm{~cm})$. A maior produtividade agronômica foi alcançada no menor espaçamento $(30 \times 10 \mathrm{~cm})$, com adubação mineral, sendo registrados $21,5 \mathrm{tha}^{-1}$, valor muito próximo ao registrado na Malásia e China onde essa hortaliça é cultivada em larga escala.
\end{abstract}

Palavras-chave: Brassica chinensis L. var. parachinensis (Bailey) Sinskaja, Brassicaceae, couve chinesa sem cabeça, hortaliça, "tsoi sum”.

\begin{abstract}
Fertilizers and spacing between plants in the yield of Malaysian cabbage

Brassica crops have been widely studied due to their importance as food for human consumption, especially in relation to their nutritional value. Both yield and consumption are high. Brassica chinensis var. parachinensis was introduced in Brazil, in Uberlândia, in 1992, surpassing other Brassica due to its high content of vitamins $A$ and $C$, calcium and iron, and being ready for consumption in about 30 days. The biological and agronomic yield of this variety was analyzed under three kinds of fertilizers and three spacings between plants with a view to its production on a commercial scale. The leaf area, dry matter mass, and absolute growth rate were higher with mineral than organic fertilizer. High values for relative growth rate and net assimilation rate were registered in plants growing in greater spacing $(30 \times 20$ and $30 \times 30 \mathrm{~cm})$. The highest value of agronomic yield was reached in the smaller spacing $(30 \times 10 \mathrm{~cm})$, with mineral fertilization, being registered $21.5 \mathrm{t} \mathrm{ha}^{-1}$. This value is near to that registered in Malaysia and China where this vegetable is cultivated on a large scale.
\end{abstract}

Keywords: Brassica chinensis L. var. parachinensis (Bailey) Sinskaja, Brassicaceae, nonheading chinese cabbage, vegetable, "tsoi sum".

\section{(Recebido para publicação em 24 de agosto de 2001 e aceito em 07 de maio de 2002)}

\begin{abstract}
A $\mathrm{s}$ inúmeras espécies de hortaliças da família Brassicaceae têm sido objeto constante de pesquisa, dada sua grande importância na alimentação humana, seja pela quantidade consumida, pelo alto valor nutricional ou por sua elevada produtividade.
\end{abstract}

Brassica chinensis L. var. parachinensis (Bailey) Sinskaja (Bailey, 1930), considerada por Opeña et al. (1988) como Brassica campestris subsp. parachinensis é originária de áreas altas do Mediterrâneo, e foi introduzida no Brasil pelo Dr. Warwick E. Kerr em 1992. Nessa variedade são encontrados $2045 \mu \mathrm{g}$ (eq caroteno) de vitamina A, $60 \mu \mathrm{g}$ de vitamina $\mathrm{C} ; 3,1 \mathrm{mg}$ de ferro e $109 \mu \mathrm{g}$ de cálcio em $100 \mathrm{~g}$ da porção comestível (Openã et al., 1988), valores que ultrapassam os registrados para o repolho (280 mg de vitamina A, 46 mg de vitamina $\mathrm{C} ; 0,8 \mathrm{mg}$ de ferro e 55 mg de cálcio). O brócolos e a couveflor só ultrapassam o valor nutricional dessa variedade em relação ao teor de vitamina C, com 111 e 72 mg em 100 g da porção comestível, respectivamente. Essa variedade é uma hortaliça anual ou bianual (Herklots, 1972), de crescimento rápido (Lee, 1982), própria para o consumo de folhas, flores e caules, sendo considerada por Herklots (1972) a mais palatável dentre as couves chinesas. Pertencente ao grupo das brássicas que não formam cabeça (0peña et al., 1988), esta hortaliça é cultivada na Malásia, China, Austrália e outros países do sudeste asiático (Bailey, 1930; Herklots, 1972; Hill, 1990), tendo sua popularidade aumentada gradativamente entre os povos não orientais (Opeña et al.,1988). Vulgarmente é de- nominada "mock pak-choi " (Bailey, 1930), "flowering white cabbage", “paak ts'oi sum” (Herklots, 1972), “tsoi sum" (Hill, 1990) ou "couve-daMalásia”, adotada no Brasil.

Trabalhando com algumas couves chinesas no sul da Austrália Ocidental, Hill (1990) verificou para "tsoi sum", que a maior produtividade $\left(46,1 \mathrm{t} \mathrm{ha}^{-1}\right)$ foi obtida no espaçamento $10 \times 10 \mathrm{~cm}$, com aplicação parcelada de $200 \mathrm{~kg} \mathrm{ha}^{-1}$ de nitrogênio na forma de $\mathrm{NH}_{4} \mathrm{NO}_{3}$. Cultivada na Província Kwangtung (China), os maiores valores de produtividade alcançados variaram de 24,3 a 28,8 $\mathrm{t} \mathrm{ha}^{-1}$, com aplicação de 45, $90 \mathrm{e}$ $135 \mathrm{~kg} \mathrm{ha}^{-1}$ de nitrogênio e espaçamentos de 10x10 e 20x20 cm (Yip et al., 1976). Na Malásia, a produtividade média obtida no cultivo dessa variedade está entre 11 e 20 t ha $^{-1}$ (Hill, 1990). 
O objetivo desse trabalho foi avaliar a produtividade biológica e agronômica de Brassica chinensis var. parachinensis cultivada com três tipos de fertilizantes e três espaçamentos entre plantas.

\section{MATERIAL E MÉTODOS}

As sementes de couve-da-Malásia (Brassica chinensis var. parachinensis) utilizadas no experimento foram obtidas na Universidade Federal de Uberlândia, a partir da multiplicação, nessa mesma Instituição, de material trazido da Malásia pelo Dr. Warwick Kerr, em 1992.

$\mathrm{O}$ experimento foi instalado em campo, na Universidade Federal de Uberlândia, de 05 de março a 05 de junho de 1993. O solo utilizado foi do tipo LATOSSOLO VERMELHO Distrófico típico, com 78 dag $\mathrm{kg}^{-1}$ de argila (Rodrigues et al., 1998) e teor médio de matéria orgânica $(3,7 \mathrm{dag} /$ $\mathrm{kg})$. A região do município de Uberlândia é caracterizada pelo tipo climático Aw, segundo o sistema de classificação de Koeppen de 1948, tendo verão chuvoso (outubro a março) e inverno seco (abril a setembro).

As mudas foram produzidas em sementeiras com 128 células, utilizandose substrato comercial (Plantimax). A semeadura foi feita nos dias 05, 06 e 07/ 03/93, colocando-se duas sementes por célula, a $0,5 \mathrm{~cm}$ de profundidade. Após a emergência das plântulas foi feito o desbaste, mantendo-se uma plântula por célula. A irrigação foi feita diariamente e, 26 dias após a semeadura, as mudas foram transplantadas para os canteiros definitivos.

O delineamento experimental foi o de blocos casualizados, com três repetições, em esquema fatorial $3 \times 3$, sendo três tipos de fertilizantes (adubo mineral, esterco de gado e esterco de galinha) e três espaçamentos entre plantas $(10,20$ e 30 $\mathrm{cm}$ ), sendo $30 \mathrm{~cm}$ entre fileiras.

A adubação mineral foi feita com base nos resultados da análise química do solo, realizada antes da instalação do experimento ( $\mathrm{pH}$ em água 6,$4 ; \mathrm{P}=4,5$ $\mathrm{mg} \mathrm{dm}{ }^{-3} ; \mathrm{K}=47 \mathrm{mg} \mathrm{dm}^{-3} ; \mathrm{Al}, \mathrm{Ca}, \mathrm{Mg}$, $\mathrm{H}+\mathrm{Al}$, soma de bases, capacidade de troca catiônica efetiva, capacidade de tro- ca catiônica a pH 7,0=0,0;4,8;0,4;2,6; 5,$3 ; 5 ; 8 \mathrm{cmol} \mathrm{dm}^{-3}$, respectivamente; saturação de bases $=67 \%$; saturação de alumínio=0), e na recomendação do que é sugerido para o cultivo de alface. Foram aplicados $833 \mathrm{~kg} \mathrm{ha}^{-1} \mathrm{de}$ superfosfato simples, $150 \mathrm{~kg} / \mathrm{ha}$ de sulfato de amônio e $150 \mathrm{~kg} \mathrm{ha}^{-1}$ de cloreto de potássio. Nas parcelas com esterco de gado foram colocados $2 \mathrm{~kg} \mathrm{~m}^{-1} \mathrm{e}$ com esterco de galinha $0,5 \mathrm{~kg} \mathrm{~m}^{-1}$, sendo ambas as fontes de fertilizantes utilizadas puras e após fermentação completa (esterco sem cama e bem curado). As quantidades desses fertilizantes orgânicos aplicadas foram definidas com base na análise de solo, na recomendação e na composição genérica desse tipo de fertilizante. Em todos os tratamentos os adubos foram espalhados e incorporados ao leito dos canteiros dois dias antes do plantio das mudas.

O transplantio das mudas foi feito em 31/03, 01 e 02/04/1993. Em cada parcela, representada por um canteiro, foram plantadas 80 mudas. A irrigação foi feita por aspersão, diariamente, exceto nos dias com alta precipitação. Nas parcelas com adubação mineral foi feita adubação nitrogenada em cobertura com 200 $\mathrm{kg} \mathrm{ha}^{-1}$ de sulfato de amônio, aos 15 dias após o transplantio das mudas.

A produtividade biológica, avaliada pela taxa de crescimento absoluto, taxa de crescimento relativo, taxa assimilatória líquida e razão de área foliar, foi calculada segundo recomendações, conceitos e expressões matemáticas descritas por Hunt (1978, 1982), Benincasa (1988) e Coombs \& Hall (1989). O intervalo entre as duas coletas, necessário para o cálculo da produtividade biológica, foi de oito dias. De cada parcela foram retiradas seis plantas, respeitando-se a bordadura de cada uma, sendo a primeira coleta feita aos 43 dias após a semeadura. As plantas retiradas para análise foram coletadas sem o sistema radicular. Para elas foram obtidos os valores de área foliar e massa da matéria seca, com secagem em estufa a $70^{\circ} \mathrm{C}$ até massa constante.

A área foliar na primeira coleta foi obtida por meio de moldes feitos em papel milimetrado, considerando-se as folhas totalmente expandidas da planta, exceto as senescentes. Com os valores obtidos para 745 folhas (área foliar real), foi calculado o fator de correção (F: AF/ $\mathrm{C} \mathrm{L}$, onde $\mathrm{AF}$ : área foliar, $\mathrm{C}$ : comprimento da lâmina foliar, L: largura máxima da lâmina foliar) segundo Benincasa (1988). Em seguida, foi calculado o valor médio do fator de correção. Os valores da área foliar real e da área foliar estimada pelo fator de correção médio foram comparados pelo teste t de "Student". Na segunda coleta a área foliar foi determinada utilizandose o fator de correção médio obtido $[\mathrm{AF}=(\mathrm{C} \mathrm{L}) \mathrm{F}]$.

Para o cálculo da produtividade agronômica foram obtidas informações referentes à massa da matéria fresca $(\mathrm{kg}$ $\left.\mathrm{ha}^{-1}\right)$ e número de sementes por grama. Também foram coletadas informações referentes ao número de frutos por planta e número de sementes por fruto. Para avaliar a produção de matéria fresca, a parte aérea de 40 plantas por parcela foi coletada e pesada aos 54 dias da semeadura. Os dados referentes à produção de frutos foram coletados aos 92 dias da semeadura, analisando-se oito plantas por parcela. A determinação do número de sementes por fruto e do número de sementes por grama foi feita com base em 40 frutos por parcela, coletados aleatoriamente aos 92 dias da semeadura.

Os dados obtidos foram inicialmente submetidos aos testes de normalidade (Shapiro-Wilk) e homogeneidade (Bartlett) para se determinar, caso necessário, a transformação adequada para cada característica analisada. Posteriormente os dados foram submetidos à análise da variância e teste de Tukey a 5\% de probabilidade. Como os dados obtidos para taxa de crescimento relativo (TCR), taxa de crescimento absoluto (TCA), número de frutos por planta, número de sementes por fruto e número de sementes por grama mostraram normalidade e homogeneidade, nenhuma transformação foi adotada. Os dados referentes à taxa assimilatória líquida (TAL), área foliar da segunda coleta, massa da matéria seca e massa da matéria fresca foram transformados para raiz quadrada; os dados de área foliar da primeira coleta sofreram transformação logarítmica $(\log x+1,0)$ e os de razão de área foliar (RAF) também foram transformados para $\log \mathrm{x}$. 
Tabela 1. Fertilizantes e espaçamento entre plantas na área foliar (AF) e massa da matéria seca (MMS) da parte aérea de Brassica chinensis var. parachinensis ${ }^{1}$. Uberlândia, UFU, 1993.

\begin{tabular}{|c|c|c|c|c|c|c|}
\hline $\begin{array}{c}\text { Caráter } \\
\text { analisado }\end{array}$ & $\begin{array}{c}\text { Espaçamento } \\
(\mathrm{cm})\end{array}$ & Adubação mineral ${ }^{2}$ & Esterco de gado ${ }^{2}$ & Esterco de galinha ${ }^{2}$ & Média & Pressuposições da análise \\
\hline \multirow[t]{4}{*}{$\mathrm{AF1}\left(\mathrm{dm}^{2}\right)$} & $30 \times 10$ & $3,2321 \pm 2,5175 \mathrm{aA}$ & $1,2093 \pm 0,7000 \mathrm{aA}$ & $1,1268 \pm 0,2029 \mathrm{aA}$ & $1,8561 \mathrm{a}$ & $W=0,9636$ \\
\hline & $30 \times 20$ & $3,0384 \pm 0,9224 \mathrm{aA}$ & $1,0638 \pm 0,5415 \mathrm{aA}$ & $0,8413 \pm 0,2297 \mathrm{aA}$ & 1,6478 a & Bartlett $_{\text {fertilizante }}=7,9590$ \\
\hline & $30 \times 30$ & $1,4401 \pm 0,9020 \mathrm{aA}$ & $3,6455 \pm 4,3131 \mathrm{aA}$ & $0,8075 \pm 0,2711 \mathrm{aA}$ & 1,9644 a & Bartlett $_{\text {espacamento }}=0,1996$ \\
\hline & Média & $2,5702 \mathrm{~A}$ & $1,9729 \mathrm{AB}$ & $0,9252 \mathrm{~B}$ & & \\
\hline \multicolumn{7}{|c|}{$\mathrm{CV}(\%)=45,94 ; \mathrm{F}_{\text {fertilizante }}=3,69^{*} ; \mathrm{F}_{\text {espacamento }}=0,04 ; \mathrm{F}_{\text {blocos }}=0,67 ; \mathrm{F}_{\text {espacamento }}$ fertilizante $=1,61$} \\
\hline \multirow[t]{4}{*}{ AF2 $\left(\mathrm{dm}^{2}\right)$} & $30 \times 10$ & $5,4230 \pm 2,1809 \mathrm{aA}$ & $1,8719 \pm 1,1566 \mathrm{aB}$ & $1,2147 \pm 0,2062 \mathrm{aB}$ & $2,8365 \mathrm{a}$ & $W=0,9754$ \\
\hline & $30 \times 20$ & $7,5197 \pm 0,8693 \mathrm{aA}$ & $1,7165 \pm 0,5175 \mathrm{aB}$ & $2,1647 \pm 0,8692 \mathrm{aB}$ & 3,8003 a & Bartlett $_{\text {fertilizante }}=0,8806$ \\
\hline & $30 \times 30$ & $5,8768 \pm 1,8458$ aA & $3,0009 \pm 0,7582 \mathrm{aAB}$ & $1,5540 \pm 0,8613 \mathrm{aB}$ & 3,4772 a & Bartlett ${ }_{\text {espacamento }}=0,2906$ \\
\hline & Média & $6,2732 \mathrm{~A}$ & $2,1964 \mathrm{~B}$ & $1,6445 \mathrm{~B}$ & & \\
\hline \multicolumn{7}{|c|}{$C V(\%)=19,36 ; F_{\text {fertilizante }}=34,90^{* *} ; F_{\text {espacamento }}=1,57 ; F_{\text {blocos }}=0,47 ; F_{\text {espacamento }}$ fertilizante $=1,16$} \\
\hline \multirow[t]{4}{*}{$\mathrm{MMS}_{1}(\mathrm{~g})$} & $30 \times 10$ & $1,4813 \pm 1,0389 \mathrm{aA}$ & $0,5834 \pm 0,3203 \mathrm{aA}$ & $0,4906 \pm 0,2215 \mathrm{aA}$ & $0,8518 a$ & $W=0,9920$ \\
\hline & $30 \times 20$ & $1,7094 \pm 0,1266 \mathrm{aA}$ & $0,5446 \pm 0,2886 \mathrm{aB}$ & $0,5892 \pm 0,2674 \mathrm{aB}$ & 0,9478 a & Bartlett $_{\text {fertilizante }}=4,9097$ \\
\hline & $30 \times 30$ & $0,7674 \pm 0,3122 \mathrm{aA}$ & $0,5732 \pm 0,0807 \mathrm{aA}$ & $0,3904 \pm 0,2313 \mathrm{aA}$ & $0,5770 \mathrm{a}$ & Bartlett ${ }_{\text {espacamento }}=3,9536$ \\
\hline & Média & $1,3194 \mathrm{~A}$ & $0,5671 \mathrm{~B}$ & $0,4901 \mathrm{~B}$ & & \\
\hline \multicolumn{7}{|c|}{$\mathrm{CV}(\%)=26,74 ; \mathrm{F}_{\text {fertilizante }}=9,55^{* *} ; \mathrm{F}_{\text {espacamento }}=1,54 ; \mathrm{F}_{\text {blocos }}=0,52 ; \mathrm{F}_{\text {espacamento fertilizante }}=0,89$} \\
\hline \multirow[t]{4}{*}{$\mathrm{MM}_{2}(\mathrm{~g})$} & $30 \times 10$ & $3,3634 \pm 1,2979 a \mathrm{~A}$ & $1,2196 \pm 0,7619 \mathrm{aA}$ & $1,1058 \pm 0,2894 \mathrm{aA}$ & $1,8963 \mathrm{a}$ & $W=0,9788$ \\
\hline & $30 \times 20$ & $5,4431 \pm 0,8402 \mathrm{aA}$ & $1,2610 \pm 0,3355 \mathrm{aB}$ & $2,4609 \pm 1,2464 \mathrm{aAB}$ & $3,0550 \mathrm{a}$ & Bartlett $_{\text {fertilizante }}=1,4442$ \\
\hline & $30 \times 30$ & $4,7084 \pm 2,8416 \mathrm{aA}$ & $2,2152 \pm 0,6660 \mathrm{aAB}$ & $1,1751 \pm 0,6993 \mathrm{aB}$ & 2,6996 a & Bartlett $_{\text {espacamento }}=0,5442$ \\
\hline & Média & $4,5050 \mathrm{~A}$ & $1,5653 \mathrm{~B}$ & $1,5806 \mathrm{~B}$ & & \\
\hline
\end{tabular}

${ }^{1}$ Números seguidos de mesma letra maiúscula na linha e minúscula na coluna não diferem significativamente a $5 \%$ pelo teste de Tukey; ${ }^{2}$ Média \pm desvio padrão (dados originais); W: Teste de Shapiro-Wilk $(\alpha=0,05)$; valores em negrito indicam normalidade da população; Valores em negrito para o teste de Bartlett $(\alpha=0,05)$ indicam homogeneidade entre as variâncias; F: Teste de Snedecor; ${ }^{* *}$ significativo a $1 \%$ de probabilidade; "significativo a $5 \%$ de probabilidade; CV: coeficiente de variação.

\section{RESULTADOS E DISCUSSÃO}

Não há registros na literatura referentes à área foliar da couve-da-Malásia. Assim, o primeiro procedimento adotado neste trabalho foi calcular o fator de correção da variedade para facilitar os cálculos envolvidos na obtenção da produtividade biológica. Como não houve diferença significativa a $1 \%$ de probabilidade entre a média da área foliar real ( $34,47 \pm 25,08 ;$ média \pm desvio padrão) e a média da área foliar estimada ( 34,60 $\pm 25,17$; média \pm desvio padrão), quando comparadas pelo teste $t$ de "Student" $(\mathrm{t}=0,0976)$, o fator de correção obtido de 0,75 foi considerado válido para $o$ cálculo da área foliar da variedade.

Não foi registrada interação significativa entre o tipo de fertilizante e o espaçamento entre plantas, para nenhuma das características analisadas (Tabelas 1-3). Efeito significativo do tipo de fertilizante foi detectado analisando-se $\mathrm{a}$ área foliar e a massa da matéria seca; efeito significativo do espaçamento entre plantas foi verificado analisando-se a TCR e TAL e o efeito significativo de ambos os fatores foi detectado para a TCA, massa da matéria fresca e número de sementes por fruto (Tabelas 1-3). Não foi verificado efeito significativo quanto ao tipo de fertilizante, nem quanto ao espaçamento entre plantas para RAF, número de frutos por planta e número de sementes por grama (Tabelas 2-3).

Os altos valores do coeficiente de variação obtidos para todas as características analisadas indicam que a variedade em estudo é um material geneticamente heterogêneo. Isso indica que trabalhos de melhoramento genético para as condições edafoclimáticas do Brasil devem ser realizados para que essa variedade possa ser explorada comercialmente. Os menores valores desses coeficientes foram registrados para área foliar no final da fase vegetativa $\left(\mathrm{AF}_{2}\right.$, tabela 1), para número de sementes por grama e número de sementes por fruto (Tabela 3). Esses resultados indicam que essas características são mais homogêneas na variedade em estudo, conferindo-lhe bom potencial agronômico como hortaliça e planta fornecedora de sementes.

A produtividade biológica da couve-da-Malásia foi significativamente maior com adubo mineral, em relação aos demais tipos de fertilizantes, no que se refere à área foliar e massa de matéria seca, nas duas coletas (Tabela 1). Esse maior incremento de matéria orgânica em oito dias permitiu às plantas submetidas a esse tipo de fertilizante alcançar maior taxa de crescimento absoluto (Tabela 2). Quando comparados com os adubos orgânicos, os adubos minerais caracterizam-se pela liberação rápida no solo de maior quantidade de íons assimiláveis pelas plantas (CFSEMG, 1999), o que certamente explica o resultado obtido neste experimento, especialmente em decorrência do ciclo curto das plantas.

Alta produtividade biológica, constatada pela maior taxa de crescimento relativo e maior taxa assimilatória líqui- 
W. R. Ferreira et al.

Tabela 2. Fertilizantes e espaçamento entre plantas na produtividade biológica de Brassica chinensis var. parachinensis ${ }^{1}$. Uberlândia, UFU, 1993.

\begin{tabular}{|c|c|c|c|c|c|c|}
\hline $\begin{array}{c}\text { Caráter } \\
\text { analisado }\end{array}$ & $\begin{array}{l}\text { Espaça- } \\
\text { mento }(\mathrm{cm})\end{array}$ & Adubação mineral $^{2}$ & Esterco de gado ${ }^{2}$ & Esterco de galinha ${ }^{2}$ & Média & Pressuposições da análise \\
\hline \multirow[t]{4}{*}{ TCA $\left(\right.$ g dia- $\left.^{-1}\right)$} & $30 \times 10$ & $0,2353 \pm 0,0475 \mathrm{bA}$ & $0,0795 \pm 0,0614 \mathrm{aA}$ & $0,0769 \pm 0,0097 \mathrm{aA}$ & 0,1306 a & $W=0,9274$ \\
\hline & $30 \times 20$ & $0,4667 \pm 0,1060 \mathrm{abA}$ & $0,0896 \pm 0,0097 \mathrm{aB}$ & $0,2340 \pm 0,1237 \mathrm{aAB}$ & $0,2634 a$ & Bartlett $_{\text {fertilizante }}=8,2044$ \\
\hline & $30 \times 30$ & $0,4926 \pm 0,3205 \mathrm{aA}$ & $0,2052 \pm 0,0789 \mathrm{aB}$ & $0,0981 \pm 0,0587 \mathrm{aB}$ & $0,2653 a$ & Bartlett $_{\text {espaçamento }}=6,8174$ \\
\hline & Média & $0,3982 \mathrm{~A}$ & $0,1248 \mathrm{~B}$ & $0,1363 \mathrm{~B}$ & & \\
\hline \multicolumn{7}{|c|}{ 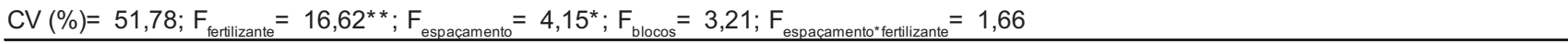 } \\
\hline TCR $\left(\mathbf{g ~ g}^{-1}\right.$ & $30 \times 10$ & $0,1303 \pm 0,0622 \mathrm{bA}$ & $0,0858 \pm 0,0319 \mathrm{bA}$ & $0,1084 \pm 0,0259 \mathrm{aA}$ & $0,1082 b$ & $W=0,9749$ \\
\hline \multirow[t]{3}{*}{ dia-1) } & $30 \times 20$ & $0,1420 \pm 0,0222 \mathrm{bA}$ & $0,1172 \pm 0,0304 a b A$ & $0,1759 \pm 0,0215 a A$ & $0,1450 \mathrm{ab}$ & Bartlett $_{\text {fertilizante }}=2,6517$ \\
\hline & $30 \times 30$ & $0,2172 \pm 0,0628 \mathrm{aA}$ & $0,1633 \pm 0,0323 \mathrm{aAB}$ & $0,1433 \pm 0,0082 \mathrm{aB}$ & 0,1746 a & Bartlett $_{\text {espacamento }}=1,0227$ \\
\hline & Média & $0,1632 \mathrm{~A}$ & $0,1221 \mathrm{~B}$ & $0,1425 \mathrm{AB}$ & & \\
\hline \multicolumn{7}{|c|}{$\mathrm{CV}(\%)=23,65 ; \mathrm{F}_{\text {fertilizante }}=3,34 ; \mathrm{F}_{\text {espacamento }}=8,76^{* *} ; \mathrm{F}_{\text {blocos }}=2,98 ; \mathrm{F}_{\text {espacamento" fertilizante }}=2,06$} \\
\hline TAL $\left(g\right.$ dm $^{-2}$ & $30 \times 10$ & $0,0723 \pm 0,0308$ aA & $0,0498 \pm 0,0142 \mathrm{aA}$ & $0,0689 \pm 0,0042 \mathrm{bA}$ & $0,0637 \mathrm{~b}$ & $W=0,9650$ \\
\hline \multirow[t]{3}{*}{ dia $\left.^{-1}\right)$} & $30 \times 20$ & $0,0986 \pm 0,0320 \mathrm{aA}$ & $0,0775 \pm 0,0232 \mathrm{aA}$ & $0,1741 \pm 0,1005 \mathrm{aA}$ & 0,1167 a & Bartlett $_{\text {fertilizante }}=1,2392$ \\
\hline & $30 \times 30$ & $0,1505 \pm 0,0653 \mathrm{aA}$ & $0,0943 \pm 0,0446 \mathrm{aA}$ & $0,0861 \pm 0,0106 \mathrm{abA}$ & $0,1103 \mathrm{ab}$ & Bartlett $_{\text {espacamento }}=4,2830$ \\
\hline & Média & $0,1071 \mathrm{~A}$ & $0,0739 \mathrm{~A}$ & $0,1097 \mathrm{~A}$ & & \\
\hline \multicolumn{7}{|c|}{$\mathrm{CV}(\%)=21,96 ; F_{\text {fertilizante }}=1,96 ; F_{\text {espacamento }}=4,24^{*} ; F_{\text {blocos }}=0,33 ; F_{\text {espaçamento }}$ fertilizante $=1,58$} \\
\hline \multirow[t]{4}{*}{$\operatorname{RAF}\left(\mathrm{dm}^{2} \mathrm{~g}^{-1}\right)$} & $30 \times 10$ & $1,8834 \pm 0,2299 \mathrm{aA}$ & $1,7756 \pm 0,1210 \mathrm{aA}$ & $1,7127 \pm 0,5461 \mathrm{aA}$ & 1,7906 a & $W=0,9529$ \\
\hline & $30 \times 20$ & $1,5420 \pm 0,1881 \mathrm{aA}$ & $1,6131 \pm 0,4155 \mathrm{aA}$ & $1,2046 \pm 0,4427 \mathrm{aA}$ & 1,4532 a & Bartlett $_{\text {fertilizante }}=5,3894$ \\
\hline & $30 \times 30$ & $1,5920 \pm 0,3098 \mathrm{aA}$ & $2,6547 \pm 1,8228 \mathrm{aA}$ & $1,7876 \pm 0,4250 \mathrm{aA}$ & $2,0114 \mathrm{a}$ & Bartlett $_{\text {espaçamento }}=4,4461$ \\
\hline & Média & $1,6725 \mathrm{~A}$ & $2,0144 \mathrm{~A}$ & $1,5683 \mathrm{~A}$ & & \\
\hline \multicolumn{7}{|c|}{$C V(\%)=63,54 ; F_{\text {fertilizante }}=1,06 ; F_{\text {espacamento }}=1,91 ; F_{\text {blocos }}=0,24 ; F_{\text {espacamento* fertilizante }}=0,55$} \\
\hline
\end{tabular}

${ }^{1}$ Números seguidos de mesma letra maiúscula na linha e minúscula na coluna não diferem significativamente a $5 \%$ pelo teste de Tukey; ${ }^{2}$ Média \pm desvio padrão (dados originais); W: Teste de Shapiro-Wilk $(\alpha=0,05)$; valores em negrito indicam normalidade da população; Valores em negrito para o teste de Bartlett $(\alpha=0,05)$ indicam homogeneidade entre as variâncias; F: Teste de Snedecor; ${ }^{* *}$ significativo a $1 \%$ de probabilidade; *significativo a $5 \%$ de probabilidade; CV: coeficiente de variação; TCA: taxa de crescimento absoluto; TCR: taxa de crescimento relativo; TAL: taxa assimilatória líquida; RAF: razão de área foliar.

da (Tabela 2) foi observada nas plantas submetidas aos maiores espaçamentos

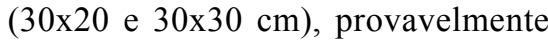
devido ao menor sombreamento entre plantas e à menor competição por água e nutrientes em relação ao espaçamento $30 \times 10 \mathrm{~cm}$. Entretanto, observações de campo mostraram que no espaçamento $30 \times 30 \mathrm{~cm}$ a área de solo disponível para o desenvolvimento das plantas não foi totalmente ocupada.

A produtividade biológica alcançada pela couve-da-Malásia, avaliada pelos valores da TCA, TCR, TAL e RAF (Tabela 2), apresentou-se dentro da faixa registrada por Dantas (1997) e Sousa (1997), apesar da época e das condições de cultivo serem diferentes. Semeada em agosto/96 em LATOSSOLO VERMELHO Distrófico típico corrigido com NPK 414-8, com aplicação foliar de molibdato de amônio a $0,1 \%$ e ácido bórico a $0,3 \%$ nas mudas de 17 e 18 dias, as plantas do tratamento testemunha do experimento realizado por Dantas (1997) alcançaram, em média, 0,313 $\mathrm{g} \mathrm{dia}^{-1}$ de TCA; 0,210 $\mathrm{g} \mathrm{g}^{-1} \mathrm{dia}^{-1}$ de TCR; 0,0848 $\mathrm{g} \mathrm{dm}^{-2} \mathrm{dia}^{-1} \mathrm{de}$ TAL e 2,862 $\mathrm{dm}^{2} \mathrm{~g}^{-1}$ de RAF, aos 29-36 dias da semeadura. As plantas testemunha do experimento realizado com a utilização de solução nutritiva regada em areia lavada, instalado em maio/1997 por Sousa (1997), apresentaram valores médios de TCA de $0,1951 \mathrm{~g} \mathrm{dia}^{-1}$, TCR de $0,1282 \mathrm{~g} \mathrm{~g}^{-1} \mathrm{dia}^{-1}$, TAL de 0,0638 $\mathrm{g} \mathrm{dm}^{-2} \mathrm{dia}^{-1}$ e RAF de $2,0342 \mathrm{dm}^{2} \mathrm{~g}^{-1}$, aos 30-37 dias após a semeadura. Essa semelhança provavelmente é conseqüência da alta variabilidade genética manifestada pelas plantas dessa variedade, o que permite que a amplitude numérica comunicada nos trabalhos, para essas características, tenha intervalos de sobreposição. Esses resultados indicam que a variedade apresenta alta plasticidade fenotípica, possibilitando assim seu cultivo em condições diversas.

Em função das discussões já apresentadas sobre o efeito de adubos minerais, compreende-se a maior produtividade agronômica, expressa pela produção de matéria fresca por área, alcançada nos tratamentos feitos com este tipo de fertilizante (Tabela 3).

Considerando-se que o número de plantas por área é fator limitante à produtividade agronômica, a utilização de plantios mais adensados leva à maior produtividade. Neste trabalho foi verificada esta relação nos tratamentos com adubo mineral, registrando-se as maiores produções de matéria fresca em espaçamentos menores (Tabela 3). Alta produtividade para a mesma variedade em cultivos adensados de 10x10 e 20×20 $\mathrm{cm}$ também foi registrada na China (Yip et al., 1976) e Austrália (Hill, 1990).

O número de frutos produzido por planta foi similar entre todos os tratamentos; porém, plantas mantidas com adubo mineral, em espaçamento $30 \times 10$ $\mathrm{cm}$, tiveram redução no número de sementes por fruto (Tabela 3). O espessamento do caule por ocasião do florescimento, a formação de perfilhos nas axilas das folhas, a presença de grande número de frutos com poucas sementes e grãos chochos observada nas plan- 
Tabela 3. Fertilizantes e espaçamento entre plantas na produtividade agronômica (MMF: massa da matéria fresca), produção de frutos e sementes em Brassica chinensis var. parachinensis ${ }^{1}$. Uberlândia, UFU, 1993.

\begin{tabular}{|c|c|c|c|c|c|c|}
\hline $\begin{array}{c}\text { Caráter } \\
\text { analisado }\end{array}$ & $\begin{array}{c}\text { Espaça- } \\
\text { mento } \\
\text { (cm) }\end{array}$ & Adubação mineral ${ }^{2}$ & Esterco de gado ${ }^{2}$ & Esterco de galinha ${ }^{2}$ & Média & $\begin{array}{c}\text { Pressuposições da } \\
\text { análise }\end{array}$ \\
\hline MMF & $30 \times 10$ & $21.516,65 \pm 8.205,74 \mathrm{aA}$ & $7.386,40 \pm 4.920,26 \mathrm{aB}$ & $6.136,06 \pm 2.979,75 \mathrm{aB}$ & $11.679,70 \mathrm{a}$ & $W=0,9734$ \\
\hline \multirow[t]{3}{*}{$\left(\mathrm{kg} \mathrm{ha}^{-1}\right)$} & $30 \times 20$ & $15.584,60 \pm 3.947,74 \mathrm{abA}$ & $3.337,07 \pm 1.271,29 \mathrm{aB}$ & $4.227,63 \pm 1.809,43 \mathrm{aB}$ & $7.716,43 \mathrm{ab}$ & Bartlett $_{\text {fertilizante }}=2,1365$ \\
\hline & $30 \times 30$ & $9.287,10 \pm 4.340,56 \mathrm{bA}$ & $3.548,42 \pm 616,68 \mathrm{aAB}$ & $2.229,40 \pm \quad 511,94 \mathrm{aB}$ & $5.021,64 \mathrm{~b}$ & Bartlett $_{\text {espacamento }}=1,8146$ \\
\hline & Média & $15.462,78 \mathrm{~A}$ & $4.757,29 \mathrm{~B}$ & $4.197,69 \mathrm{~B}$ & & \\
\hline \multicolumn{7}{|c|}{ CV $(\%)=24,38 ; F_{\text {fertilizante }}=23,59^{* *} ; F_{\text {espacamento }}=6,42^{* *} ; F_{\text {blocos }}=0,31 ; F_{\text {espacamento fertilizante }}=0,61$} \\
\hline Sementes & $30 \times 10$ & $483,33 \pm 66,71 \mathrm{aA}$ & $609,67 \pm 25,11 \mathrm{aA}$ & $545,00 \pm 76,27 \mathrm{aA}$ & 546,00 a & $W=0,9734$ \\
\hline \multirow[t]{3}{*}{ Igrama } & $30 \times 20$ & $506,33 \pm 134,66 \mathrm{aA}$ & $561,00 \pm 110,87 \mathrm{aA}$ & $456,33 \pm 113,54 \mathrm{aA}$ & 507,89 a & Bartlett $_{\text {fertilizante }}=0,2308$ \\
\hline & $30 \times 30$ & $551,17 \pm 57,51 \mathrm{aA}$ & $517,67 \pm 71,60 \mathrm{aA}$ & $523,00 \pm 97,60 \mathrm{aA}$ & 530,61 a & Bartlett $_{\text {espacamento }}=\mathbf{2 , 2 7 3 0}$ \\
\hline & Média & $513,61 \mathrm{~A}$ & $562,78 \mathrm{~A}$ & $508,11 \mathrm{~A}$ & & \\
\hline \multicolumn{7}{|c|}{$C V(\%)=17,87 ; F_{\text {fertilizante }}=0,92 ; F_{\text {espacamento }}=0,37 ; F_{\text {blocos }}=0,10 ; F_{\text {espacamento* fertilizante }}=0,73$} \\
\hline \multirow{4}{*}{$\begin{array}{l}\text { Frutos/ } \\
\text { planta }\end{array}$} & $30 \times 10$ & $37,29 \pm 42,41 \mathrm{aA}$ & $47,84 \pm 30,00 \mathrm{aA}$ & $49,38 \pm 28,20 \mathrm{aA}$ & $44,84 \mathrm{a}$ & $W=0,9664$ \\
\hline & $30 \times 20$ & $93,21 \pm 95,07$ aA & $85,13 \pm 45,64 a A$ & $80,84 \pm 25,82 \mathrm{aA}$ & 86,39 a & Bartlett $_{\text {fertilizante }}=6,2098$ \\
\hline & $30 \times 30$ & $51,80 \pm 60,62 \mathrm{aA}$ & $102,48 \pm 45,86 a A$ & $49,42 \pm 9,84 \mathrm{aA}$ & 67,90 a & Bartlett $_{\text {espacamento }}=2,5638$ \\
\hline & Média & $60,77 \mathrm{~A}$ & $78,48 \mathrm{~A}$ & $59,88 \mathrm{~A}$ & & \\
\hline \multicolumn{7}{|c|}{$C V(\%)=71,74 ; F_{\text {fertilizante }}=0,44 ; F_{\text {espaçamento }}=1$} \\
\hline \multirow{4}{*}{$\begin{array}{l}\text { Sementes } \\
\text { Ifruto }\end{array}$} & $30 \times 10$ & $9,63 \pm 3,44 \mathrm{bB}$ & $16,70 \pm 1,30 \mathrm{aA}$ & $14,62 \pm 2,50 \mathrm{aAB}$ & $13,65 b$ & $W=0,9801$ \\
\hline & $30 \times 20$ & $15,49 \pm 5,67 \mathrm{aA}$ & $19,08 \pm 1,68 \mathrm{aA}$ & $17,87 \pm 1,05 \mathrm{aA}$ & 17,48 a & Bartlett $_{\text {fertilizante }}=\mathbf{5 , 9 5 9 7}$ \\
\hline & $30 \times 30$ & $14,07 \pm 2,28 \mathrm{abA}$ & $18,00 \pm 1,90 \mathrm{aA}$ & $18,74 \pm 3,08 \mathrm{aA}$ & $16,93 \mathrm{ab}$ & Bartlett $_{\text {espacamento }}=0,4217$ \\
\hline & Média & $13,06 \mathrm{~B}$ & $17,93 \mathrm{~A}$ & $17,08 \mathrm{~A}$ & & \\
\hline \multicolumn{7}{|c|}{$C V(\%)=16,88 ; F_{\text {fertilizante }}=8,30^{* *} ; F_{\text {espaçamento }}=5,29^{*} ; F_{\text {blocos }}=2,13 ; F_{\text {espaçamento*fertilizante }}=0,53$} \\
\hline
\end{tabular}

${ }^{1}$ Números seguidos de mesma letra maiúscula na linha e minúscula na coluna não diferem significativamente a $5 \%$ pelo teste de Tukey; ${ }^{2}$ Média \pm desvio padrão (dados originais); W: Teste de Shapiro-Wilk $(\alpha=0,05)$; valores em negrito indicam normalidade da população; Valores em negrito para o teste de Bartlett $(\alpha=0,05)$ indicam homogeneidade entre as variâncias; F: Teste de Snedecor; ${ }^{* *}$ significativo a $1 \%$ de probabilidade; "significativo a $5 \%$ de probabilidade; CV: coeficiente de variação.

tas mantidas com adubo mineral, independente do espaçamento, indicam ter havido um incremento da parte vegetativa da planta em detrimento da parte reprodutiva, provavelmente em decorrência do excesso de adubação nitrogenada. Segundo Malavolta et al. (1989), de modo geral, o excesso de adubação com nitrogênio pode levar à redução na frutificação. A quantidade total de nitrogênio aplicada durante a execução deste trabalho $\left(150 \mathrm{~kg} \mathrm{ha}^{-1}\right.$ no preparo do solo $+200 \mathrm{~kg} \mathrm{ha}^{-1} \mathrm{em}$ cobertura) excedeu $150 \mathrm{~kg} \mathrm{ha}^{-1}$ em relação à quantidade máxima utilizada por Hill (1990) para o cultivo da mesma variedade na Austrália. O autor não apresentou em seu trabalho dados referentes à produção de sementes. Apesar de reduzir a quantidade de sementes por fruto, o aumento de massa vegetativa e a formação de perfilhos nas plantas podem ser interessantes do ponto de vista comercial, uma vez que, segundo Herklots (1972), essa hortaliça é própria para o consumo de folhas, flores e caule. A fim de reduzir os efeitos decorrentes de adubação inadequada, recomenda-se a realização de estudos sobre a marcha de absorção dos diferentes nutrientes por essa nova cultura, facilitando o suprimento adequado das exigências nutricionais das plantas em cada fase de seu desenvolvimento.

$\mathrm{Na}$ literatura são encontrados trabalhos com diferentes culturas, nos quais são relatados os efeitos de alguns nutrientes na produção, no tamanho e no vigor de sementes. Uma revisão feita por Sá (1994) mostra que, dependendo do nutriente, da cultura, da dose e da fase de desenvolvimento da planta em que este está sendo aplicado, podem ou não ocorrer alterações na quantidade de sementes produzida, no peso e no vigor das mesmas, tanto com relação à porcentagem e velocidade de germinação, como no vigor das plântulas. Para a couve-daMalásia, Sousa (1997) verificou que na ausência de enxofre as plantas não formam frutos; a ausência de nitrogênio e fósforo reduzem drasticamente não só $o$ número de frutos por planta, mas também a produção de sementes por fruto e o número de sementes por grama.

Apesar de ter sido registrada redução no número de sementes por fruto em plantas de couve-da-Malásia cultivadas com adubação mineral, em espaçamento $30 \times 10 \mathrm{~cm}$, não se registrou aumento na massa média final das sementes, uma vez que o número de sementes por grama não se mostrou significativamente diferente entre os tratamentos (Tabela 3). Para algumas culturas, dependendo do nutriente e da época de aplicação, observa-se relação inversa entre massa e número de sementes (Sá, 1994).

\section{AGRADECIMENTOS}

Ao Dr. Warwick Estevam Kerr pelo fornecimento das sementes, ao Sr. John David Bagnall pela revisão do abstract, à Profa. Denise Santana pelas instruções e sugestões no tratamento estatístico dos dados os autores registram seus sinceros agradecimentos. 


\section{LITERATURA CITADA}

BAILEY, L.H. The cultivated brassicas. Gentes Herbarum, v. 2, n. 5, p. 209-267, 1930.

BENINCASA, M.M.P. Análise de crescimento de plantas: noções básicas. Jaboticabal: UNESP, Faculdade de Ciências Agrárias e Veterinárias, $1988.41 \mathrm{p}$.

CFSEMG (Comissão de Fertilidade do Solo do Estado de Minas Gerais). Adubação orgânica. In RIBEIRO, A.C.; GUIMARÃES, P.T.G. ALVAREZ, V.H., eds. Recomendação para o uso de corretivos e fertilizantes em Minas Gerais: 5 Aproximação. Viçosa: Comissão de Fertilidade do Solo do Estado de Minas Gerais, 1999. p. 87-92. COOMBS, J.; HALL, D.O. Técnicas de bioprodutividade e fotossintese. Fortaleza: Edições Universidade Federal do Ceará, 1989. 290 p.

DANTAS, B.F. Efeito do metanol na produtividade de couve-da-Malásia (Brassica chinensis var parachinensis (Bailey) Sinskaja). Uberlândia: Universidade Federal de Uberlândia, 1997. 43 p. (Monografia graduação)
HERKLOTS, G.A.C. Vegetable in south-East Asia. Hong Kong: George Allen \& Unewin Ltda, $1972.525 \mathrm{p}$.

HILL, T.R. The effect of nitrogenous fertilizer and plant spacing on the yield of three Chinese vegetables - Kai lan, Tsoi sum and Pak choi. Scientia Horticulturae, v. 45, p. 11-20, 1990.

HUNT, R. Plant growth analysis. London: Edward Arnold Publishers Limited, 1978. 67 p.

HUNT, R. Plant growth curves: the functional approach to plant growth analysis. London: Edward Arnold Publishers Limited, 1982. 248 p. LEE, S.H. Vegetable crops growing in China. Scientia Horticulturae, v. 17, p. 201-209, 1982. MALAVOLTA, E.; VITTI, G.C.; OLIVEIRA, S.A. Avaliação do estado nutricional das plantas: princípios e aplicações. Piracicaba: Associação Brasileira para Pesquisa da Potassa e do Fosfato, 1989. 201 p.

OPEÑA, R.T.; KUO, C.G.; YOON, J.Y. Breeding and seed production of Chinese cabbage in the Tropics and Subtropics. Tainan, Taiwan: Asian Vegetable Research and Development Center, 1988. 92 p. (Technical Bulletin, 17).
RODRIGUES, F.A.; CORRÊA, G.F.; SANTOS, M.A.; BORGES FILHO, E.L. Fatores envolvidos na supressividade a Rhizoctonia solani em alguns solos tropicais brasileiros. Revista Brasileira de Ciência do Solo, v. 22, p. 239-246.

SÁ, M.E. Importância da adubação na qualidade de sementes. In: SÁ, M.E.; BUZZETI, S., coords Importância da adubação na qualidade dos produtos agrícolas. São Paulo: Ícone Editora Ltda, 1994. p. 65-98.

SOUSA, E.R. Efeito da nutrição mineral na produtividade de couve-da-Malásia (Brassica chinensis var parachinensis (Bailey) Sinskaja). Uberlândia: Universidade Federal de Uberlândia, 1997. 29 p. (Monografia graduação).

YIP, S.M.; PAO, C.S.; TONG, T.C.; NG, Y.S. A note on some studies of chinese flowering cabbage (Brassica parachinensis Bailey). Agric. HongKong, v. 1, n. 5, p. 407-418, 1976. 